\title{
Government Subsidies, Spatial Agglomeration and Innovation Performance_-An empirical study of industrial policy disputes
}

\author{
Rongjian $\mathrm{Yu}^{1, \mathrm{a}}$ and Jinwei Wang ${ }^{2, \mathrm{~b}^{*}}$ \\ ${ }^{1}$ School of Business Administration, Zhejiang Gongshang University, Hangzhou, China \\ ${ }^{2}$ School of Business Administration, Zhejiang Gongshang University, Hangzhou, China \\ ayurongjian@hotmail.com, b837202997@qq.com
}

Keywords: government subsidies, location choice, spatial agglomeration, innovation performance.

\begin{abstract}
This paper uses the panel data of high-tech industry enterprises to study the impact of government subsidies on enterprise innovation performance. And test whether the government subsidy policy affects the location choice of enterprises, further enhancing the spatial agglomeration, Making the government subsidy policy indirectly play an innovation effect. The empirical results show that government subsidies can actively promote the innovation performance of enterprises, but the government subsidies do not significantly affect the location choice of enterprises or enhance the spatial agglomeration of enterprises in the region. This shows that the government subsidy policy plays a single role in the innovation effect, and fails to form a close relationship with the market mechanism of the spatial agglomeration effect.
\end{abstract}

\section{Introduction}

In recent years, the government industrial policy has been controversial, especially renowned economist Professor Yifu Lin and Weiying Zhang launched a fierce academic discussion of the validity of industrial policy, sparking heated debate. The argument about the industrial policy of the government is continuous. The reason is that the industrial policy of our country has the strong direct interference at present, and has typical characteristic of the selective industrial policy, which violates the internal mechanism of the market economy to a certain extent, leading to the distortion of the market factor. Under the market economy condition, the market mechanism cannot be replaced, there are inherent laws of economic development, Professor Weiying Zhang believes that the government should try to avoid intervention in the market. However, some scholars believe that the industrial policy is of great importance. In the process of economic development, technological upgrading and industrial structure change will face the problems of coordination and externality, which need government to coordinate or solve. Some anarchists emphasized the role of the government, that the government industrial policy to support the current economic catch-up development, and achieved in the economies of scale, structural optimization, technological innovation and other aspects of the advantage, namely "economic development theory", and some scholars believe that the market itself has defects, such as asymmetric information, externality of economic activities, so need to be made up of industrial policy correction, namely "insufficient market theory", and the professor Yifu Lin argues that the government should intervene the market to ensure the economic development in the right direction coincide. The government subsidy is an important industrial policy of governments or regions to support innovation, try through financial support and other incentives for incentive market mechanism on the innovation activities of the failure, the major concern is the government subsidies to promote the enterprise innovation performance, and the government subsidy policy is to attract enterprises gathered in the region, conducive to the formation of enterprise innovation the agglomeration effect of market mechanism or government subsidy policy can promote enterprise innovation performance through the agglomeration effect of market mechanism. 


\section{Theoretical Development Analysis}

\section{1government subsidies and innovation performance}

Whether government subsidies can effectively improve the innovation performance of enterprises has always been an important focus of experts and scholars. At present, in general, theoretical basis of the study of the relationship between government subsidies and innovation performance can be divided into two schools: one is to "promote oriented" schools, including the Keynes economics theory and technology innovation theory, on the basis of these theories the view that government subsidies can improve the innovation performance; two is "inhibition oriented" schools, mainly contains the information asymmetry theory, agency theory and crowding out effect theory, takes these theories as a technological point of view of government subsidies on enterprise innovation performance have a negative impact or inhibition.

In the real economic activities, due to the existence of incomplete competition and externality, it is difficult to adjust the economic activities by relying on the invisible hand of the market mechanism. It is difficult for enterprises to reach the optimal level of innovation, and it is difficult to achieve the Pareto optimal state. Studies also show that only depends on the market economy system, the optimal level cannot make the enterprise technology innovation level to achieve the expectations of the society. Because of the spillover effect of market structure has inherent deficiencies and innovation activity, makes the enterprise innovation investment will is not strong (Tongliang An et al, 2009) ${ }^{[1]}$. According to the theory of technological innovation, the technical innovation has high risk and high investment, small and medium-sized enterprises do not have the basis of innovation resources and their weak strength is difficult to achieve a breakthrough innovation, innovation of large enterprises can afford only with a strong foundation caused by high risk and high investment, coupled with the existence of knowledge spillover effect on disclosure or in the process of innovation, reduce the innovator's return, to enable enterprises to bear more risk, so enterprises will lack of innovation to a certain extent. However, the government subsidies can directly reduce the cost of enterprise innovation, research and innovation enterprise risk sharing, Hewitt Dundas et al (2009) ${ }^{[2]}$ found that government funding to promote research and development activities and major product development, the incentive effect of subsidies on enterprise $R \& D$ investment, stimulate innovation and vitality of enterprises.

However, some scholars believe that government subsidies do not have a significant positive effect on enterprise innovation performance. According to asymmetric information and principal-agent theory, based on the asymmetry of information, the quantity or quality of information occupied by both sides of one party is inferior to the other, and the one who holds the information superiority may seek benefits for itself because of the information superiority. High government subsidies not only aggravate the financial burden, but also distort the behavior of enterprises, cause rent-seeking or commercial bribery, and even lead to vicious price competition, and ultimately damage the overall interests of the enterprise (Shuming Ren, Jing Zhang, 2013) ${ }^{\text {[3] }}$. Crowding out effect means that the increase of government subsidy funds is likely to reduce the individual R\&D expenditure of enterprises. Due to government subsidies are biased and guidance to a certain extent, the government will formulate certain provisions, only providing government subsidies to certain industries, technology and innovation projects, which leads to the enterprise will be more $R \& D$ investment to be able to get government subsidies within the scope of government subsidies for research and development the investment will be reduced. Studies have shown that there are many industrial technology, public technology and lower product technology within the scope of government subsidies, which can lead to crowding out effect on R\&D investment of medium and high technology products. Dirk Fornahl et al (2011) ${ }^{[4]}$ found that government subsidies have no significant effect on Patent Innovation of a single company based on German biotechnology firms. Jun Wang (2010) ${ }^{[5]}$ thinks that the incentive effect of government subsidies 
on patent innovation output is not significant, and the positive influence of government subsidies on enterprise independent innovation is uncertain.

\section{2spatial agglomeration and innovation performance}

Spatial agglomeration refers to the enterprise and related auxiliary department in an area within a cluster, agglomeration can provide convenient conditions for enterprise innovation activities, In the neighborhood, frequent exchanges and cooperation between enterprises frequently adjacent to promote technology transfer and learning spread in the gathering area, for help the innovation of enterprises.

Spatial agglomeration has incentive effect of innovation. Firstly, spatial agglomeration has the advantage of knowledge information dissemination. The study believes that the dissemination of technical knowledge information has the spatial boundary, and in the specific space boundary, the dissemination of technical knowledge information can achieve better results, and help the innovation activities occur. Cui Zhang (2010) ${ }^{[6]}$ thinks that there are special advantages of knowledge attribute in spatial agglomeration area, and knowledge has local attribute and tacit attribute, and the special genus of knowledge. Pinch (2003) ${ }^{[7]}$ and other scholars believe that coded knowledge is more likely to be spread and spread than enterprise proprietary knowledge, and agglomeration enterprises can promote the spread of knowledge in the scope of agglomeration space through mutual learning, thus creating innovative competitive advantage for enterprises. Secondly, the spatial agglomeration has the advantage of geographical proximity, shortens the distance between cluster enterprises, avoid the lag of information to a certain extent, and has relatively low cost of information communication, learning, experiment and innovation (Von Zedtwitz and Heimann, 2006) ${ }^{[8]}$, helping to establish cooperative relations and knowledge flow between enterprises. Enterprises close to other innovative companies will have an important role in promoting innovation (Beaudry and Breschi, 2003) ${ }^{[9]}$, the study found that in the case of industrial agglomeration, enterprises have greater enthusiasm for innovation. Schemgell \& Barber (2011) ${ }^{\text {[10] }}$ research confirms that geographical proximity can significantly influence R\&D cooperation among industrial enterprises, and provide impetus for enterprise innovation. $\mathrm{Zi} \mathrm{Wu}(2011)^{[11]}$ has proved that knowledge spillovers have obvious geographical characteristics, and R\&D effectiveness decreases with the increase of distance. Again, the spatial agglomeration of the labor market has the advantage of human resources, the same or closely related industries spatial agglomeration, easy to form a deep and diverse labor market, can make agglomeration within the region to achieve a more specialized division of labor, improve labor productivity, achieve increasing returns.

\section{3 location choice: agglomeration effect or government subsidy}

The location choice of enterprises refers to the enterprises to evaluate the location selection factors through some evaluation strategies to determine the optimal investment and management location, including the choice of economic regions and the determination of enterprise selection. The location selection of enterprises mainly includes three aspects: the location choice of newly established enterprises, the location choice that enterprises decide to retain the existing location or

move to the new location, and the expansion of the enterprise itself. Svetlicic (2010) ${ }^{[12]}$ study shows that agglomeration can strengthen enterprise advantage, enterprise location selection effect by three kinds of effects are as follows: resources endowment effect, which is rich in natural resources or specialized labor market; agglomeration effect, namely "self-reinforcing trend" or "accumulation effect" (Fujita \& Thisse, 2013) ${ }^{[13]}$; the guide effect of the policy, namely the government to formulate preferential policies to actively put into effect of enterprise location selection, externality agglomeration can have a significant impact on (Guoqiang Cui, 2012) ${ }^{[14]}$. Agglomeration factor is an important aspect that enterprises must consider in location selection. It can be attributed to the agglomeration effect of many enterprises due to the proximity of geographical space, including specialization, reducing the transaction cost, enterprise collaboration, knowledge sharing and information technology diffusion. Because the agglomeration region exists agglomeration effect, making enterprises in the region can be obtained by other enterprises cannot 
get the advantages of production and operation enterprises within the region are improved, the externality of agglomeration advantages will inevitably affect the spatial layout of the enterprise, there is bound to influence between agglomeration and enterprise location.

Although the agglomeration of enterprise space can produce location factors to attract enterprise location choice, but agglomeration will also have some adverse factors, such as the existence of fierce competition in the spatial agglomeration, even vicious resistance, and "free rider" phenomenon. This requires the role of government participation, the implementation of preferential subsidies necessary, to offset the impact of unfavorable factors. The government introduced a series of policies and incentive measures, including government subsidies, tax incentives, subsidized loans and other preferential policies, including government subsidies is an important factor in location choice must be considering the enterprise. Lei $\mathrm{Xu}$ (2013) ${ }^{[15]}$ through the establishment of C-P model, and the introduction of the government departments to analyze the influence and role of government distribution in manufacturing enterprises. The results show that the role of government participation, especially government subsidy policy, to improve the cohesion of the enterprise manufacturing industry to a certain extent, the manufacturing industry enterprise location choice is more concentrated in in a specific area. Through the subsidy policy, the system construction and the public facility investment construction and so on, the government can influence the development direction of the factor endowment, and exert the regional factor endowment comparative advantage, and affect the enterprise location choice decision (Chenguang $\mathrm{Hu}, 2011)^{[16]}$. However, the government policy incentives also have limitations to some extent. Because of the similar policy competition between regions, the policy incentive effect area of a region's capital location choice weakens. From another point of view, the government policy incentive is started from the regional demand, while the capital flow does not depend on the region's own needs, to a certain extent, ignores the real needs of capital flow.

\section{Research Design}

\section{1data sources and sample selection}

The data used in this paper are derived from the Chinese industrial enterprise database, which is counted as the annual data and set up by the National Bureau of statistics. According to the "high technology industry (Manufacturing) classification (2013)" and "high tech industry classification statistics directory" (the word [2002]33), choose the medicine manufacturing industry, special equipment manufacturing, transportation equipment manufacturing, electronic and communication equipment manufacturing, instrumentation and office equipment manufacturing industry of high technology the industry, according to the "national industry classification (GB/T-2002)" selected industries. Contains variables related to lack of enterprise after excluding cases, given the available data limitations, and the standard of statistical data of industrial enterprise database (Loren Brandt, 2014) ${ }^{[17]}$, that the period from 2005 to 2007 data is most consistent with the research requirements, ultimately selected obtained high technology industrial enterprises in Zhejiang province 3830.

\section{2 definition of variables}

Dependent variable, in measuring the innovation performance of enterprises, this paper selects the output value of new products as the variables to measure the innovation performance of enterprises, and uses NP to express the innovation performance of enterprises.

Independent variable, this paper selects the government subsidies income value to measure the government subsidy policy, which reflects the direct subsidy amount of the government subsidy policy to the enterprise, which is expressed by Gov_subs.

Intermediary variable, this paper focused on the government subsidy policy implementation process, can cause industrial agglomeration in the geographic area, the formation of innovative agglomeration effect of market mechanism, according to the geographic agglomeration degree said calculation method using Martin (2011) ${ }^{[18]}$ method to construct industrial cluster variables, through 
the city other companies in the industry of employment scale to measure the degree of agglomeration, represented by Geo_agg.

Control variables, considering the influence of other factors on innovation, based on existing research experience, this paper selects the research and development costs, the main business income, enterprise age, total assets, staff factors as control variables, respectively, by RD, BI, age, assets, staff.

\section{3model design}

By referring to the mediation effect theory (Zhonglin Wen, Baojuan Ye, 2014) ${ }^{[19]}$, and combining the research content, the following models are constructed:

$$
\begin{aligned}
& \mathrm{NP}_{\mathrm{i}, \mathrm{t}}=\alpha_{0}+\alpha_{1} \text { Gov_subs }_{\mathrm{i}, \mathrm{t}}+\alpha_{2} \mathrm{RD}_{\mathrm{i}, \mathrm{t}}+\alpha_{3} \mathrm{BI}_{\mathrm{i}, \mathrm{t}}+\alpha_{4} \text { age }_{\mathrm{i}, \mathrm{t}}+\alpha_{5} \text { assets }_{\mathrm{i}, \mathrm{t}}+\alpha_{6} \text { Staff }_{\mathrm{i}, \mathrm{t}}+\varepsilon_{\mathrm{i}, \mathrm{t}}(1)
\end{aligned}
$$

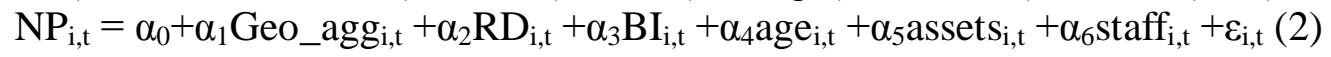

$$
\begin{aligned}
& \text { Geo_agg }_{i, t}=\alpha_{0}+\alpha_{1} \text { Gov_subs }_{i, t}+\alpha_{2} \mathrm{RD}_{\mathrm{i}, \mathrm{t}}+\alpha_{3} \mathrm{BI}_{\mathrm{i}, \mathrm{t}}+\alpha_{4} \text { age }_{\mathrm{i}, \mathrm{t}}+\alpha_{5} \text { assets }_{\mathrm{i}, \mathrm{t}}+\alpha_{6} \text { staff }_{\mathrm{i}, \mathrm{t}}+\varepsilon_{\mathrm{i}, \mathrm{t}}(3) \\
& \mathrm{NP}_{\mathrm{i}, \mathrm{t}}=\alpha_{0}+\alpha_{1} \text { Gov_subs }_{\mathrm{i}, \mathrm{t}}+\alpha_{2} \mathrm{Geo}_{\text {aggg }} \mathrm{it, \textrm {t }}+\alpha_{3} \mathrm{RD}_{\mathrm{i}, \mathrm{t}}+\alpha_{4} \mathrm{BI}_{\mathrm{i}, \mathrm{t}}+\alpha_{5} \text { age }_{\mathrm{i}, \mathrm{t}}+\alpha_{6} \text { assets }_{\mathrm{i}, \mathrm{t}}+\alpha_{7} \text { staff }_{\mathrm{i}, \mathrm{t}}+\varepsilon_{\mathrm{i}, \mathrm{t}}(4) \\
& \mathrm{NPi}, \mathrm{t}=\alpha_{0}+\alpha_{1} \text { Gov_subsi,t }+\alpha_{2} \text { Gov_subsi,t }{ }^{\wedge} 2+\alpha_{3} \text { RDi,t }+\alpha_{4} \text { BIi,t }+\alpha_{5} \text { agei,t }+\alpha_{6} \text { assetsi,t }+\alpha_{7} \text { staffi,t } \\
& +\varepsilon i, t(5)
\end{aligned}
$$

\section{Empirical Analysis}

\section{1 descriptive statistics}

Table 4-1 shows the descriptive statistics of variables, it can be seen that the average output value of new products increased with years of change, found that in 2006 new product output value over the previous year growth rate of $39.40 \%$, in 2007 the output value of new products last year with a growth rate of $43.25 \%$, that the whole enterprise innovation performance upgrade however, the new product output value of standard deviation is large, there is a big difference, which shows that there is a big difference between enterprise's innovation performance. Similarly, the standard deviation of government subsidies has a large fluctuation, which shows that there is a big difference between the government subsidy funds enjoyed by enterprises. Through the observation of geographic concentration level data, the standard deviation of little fluctuation, through geographical agglomeration degree changes of image can be seen, the geographical agglomeration

\begin{tabular}{|c|c|c|c|c|c|c|c|c|c|}
\hline variables & years & $\begin{array}{l}\text { sample } \\
\text { size }\end{array}$ & $\begin{array}{l}\text { mean } \\
\text { value }\end{array}$ & median & $\begin{array}{c}\text { trimmed } \\
\text { mean }\end{array}$ & $\begin{array}{l}\text { standard } \\
\text { deviation }\end{array}$ & $\begin{array}{c}\text { median } \\
\text { absolute } \\
\text { deviation }\end{array}$ & $\begin{array}{c}\text { Min } \\
\text { value }\end{array}$ & Max value \\
\hline \multirow{3}{*}{ NP } & 2005 & 3830 & 12723.54 & 0 & 474.69 & 137800 & 0 & 0 & 6908326 \\
\hline & 2006 & 3830 & 17736.84 & 0 & 1324.32 & 146797.19 & 0 & 0 & 5873367 \\
\hline & 2007 & 3830 & 25407.99 & 0 & 1983.98 & 243537.22 & 0 & 0 & 10238881 \\
\hline \multirow[t]{3}{*}{ Gov subs } & 2005 & 3830 & 298.70 & 0 & 13.48 & 4812.54 & 0 & 0 & 255988 \\
\hline & 2006 & 3830 & 252.59 & 0 & 19.70 & 1757.95 & 0 & 0 & 60368 \\
\hline & 2007 & 3830 & 264.53 & 0 & 26.09 & 1974.23 & 0 & 0 & 71217 \\
\hline \multirow{3}{*}{$\begin{array}{c}\mathrm{Geo} \_ \\
\text {agg }\end{array}$} & 2005 & 3830 & 45735.30 & 41659 & 45163.64 & 28083.79 & 32354.78 & 123 & 92377 \\
\hline & 2006 & 3830 & 53198.92 & 52298 & 51840.12 & 33677.21 & 43189.62 & 245 & 113261 \\
\hline & 2007 & 3830 & 59078.10 & 51008 & 57963.33 & 37613.76 & 38267.39 & 150 & 122051 \\
\hline \multirow{3}{*}{$\mathrm{RD}$} & 2005 & 3830 & 1519.34 & 0 & 67.76 & 25943.80 & 0 & 0 & 1426446 \\
\hline & 2006 & 3830 & 1884.49 & 0 & 115.00 & 24642.28 & 0 & 0 & 1029125 \\
\hline & 2007 & 3830 & 905.10 & 0 & 73.64 & 10057.46 & 0 & 0 & 520886 \\
\hline \multirow{3}{*}{ BI } & 2005 & 3830 & 64509.91 & 15086 & 20985.55 & 550426.30 & 11830.41 & 5000 & 25214885 \\
\hline & 2006 & 3830 & 84281.44 & 18057 & 25786.47 & 84333.97 & 14805.98 & 5001 & 33424668 \\
\hline & 2007 & 3830 & 96379.89 & 21071 & 30061.83 & 919324.70 & 17662.96 & 5000 & 40846801 \\
\hline
\end{tabular}
degree showed an increasing trend, but the increase is relatively small, that agglomeration in the space changing, not very obviously.

Table 4-1. descriptive statistical analysis of variables 
Table 4-1 cont.

\begin{tabular}{c|c|c|c|c|c|c|c|c|c}
\hline \multirow{3}{*}{ age } & 2005 & 3830 & 7.71 & 6 & 6.47 & 7.20 & 4.45 & 0 & 79 \\
\cline { 2 - 11 } & 2006 & 3830 & 8.66 & 7 & 7.45 & 7.14 & 4.45 & 0 & 80 \\
\cline { 2 - 11 } & 2007 & 3830 & 9.64 & 8 & 8.44 & 7.09 & 4.45 & 0 & 81 \\
\hline \multirow{5}{*}{ assets } & 2005 & 3830 & 59283.61 & 13792 & 20311.35 & 375641.38 & 12679.94 & 618 & 16847103 \\
& & & & & & & & & \\
\cline { 2 - 11 } & 2006 & 3830 & 69091.79 & 16592 & 24482.84 & 433187.44 & 15261.14 & 1143 & 20070847 \\
\cline { 2 - 10 } & 2007 & 3830 & 80791.49 & 19307 & 28732.17 & 512023.59 & 17784.53 & 1063 & 23446379 \\
\hline \multirow{3}{*}{ staff } & 2005 & 3830 & 181.47 & 91 & 112.99 & 557.34 & 68.20 & 4 & 24420 \\
\cline { 2 - 10 } & 2006 & 3830 & 195.60 & 99 & 121.81 & 521.77 & 74.13 & 8 & 17768 \\
\cline { 2 - 10 } & 2007 & 3830 & 203.37 & 100 & 125.59 & 557.22 & 75.61 & 5 & 17850 \\
\hline
\end{tabular}

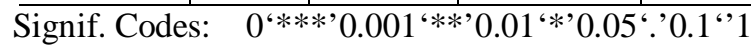

\section{2 correlation analysis}

Table 4-2 shows the correlation between variables and the significance level test preliminary results, through the observation that the output value of new products and government subsidies showed a positive correlation at the $1 \%$ level, output value of new products and geographic concentration level showed a positive correlation at the level of $5 \%$ degree. However, there is no significant correlation between government subsidies and geographical agglomeration, and further test results need to be further analyzed.

Table 4-2. correlation between variables and significant level test analysis

\begin{tabular}{|c|c|c|c|c|c|c|c|c|}
\hline & NP & Gov_subs & Geo_agg & $\mathrm{RD}$ & BI & age & assets & staff \\
\hline NP & 1.0000 & & & & & & & \\
\hline Gov_subs & $0.1988^{* *}$ & 1.0000 & & & & & & \\
\hline Geo_agg & $0.0005^{*}$ & -0.0065 & 1.0000 & & & & & \\
\hline $\mathrm{RD}$ & $0.5306^{* * *}$ & $0.0748^{* * *}$ & 0.0048 & 1.0000 & & & & \\
\hline BI & $0.5190^{* *}$ & $0.2606^{* * *}$ & 0.0038 & $0.1972^{* *}$ & 1.0000 & & & \\
\hline age & $0.0518^{* * *}$ & $0.0210^{*}$ & $-0.0294 *$ & $0.0549 * *$ & $0.0364 * *$ & 1.0000 & & \\
\hline assets & $0.5692^{* *}$ & $0.3236^{* *}$ & -0.0084 & $0.2800^{* * *}$ & $0.8448^{* * *}$ & $0.0751^{* * *}$ & 1.0000 & \\
\hline staff & $0.4971^{* *}$ & $0.2641^{* *}$ & $0.0013^{*}$ & $0.2376^{* *}$ & $0.6204^{* *}$ & $0.1052^{* *}$ & $0.8080^{* *}$ & 1.0000 \\
\hline
\end{tabular}

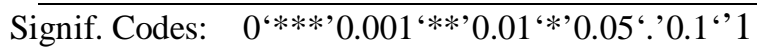

\section{3 model estimation results and test results}

For panel data, need to choose random effects or fixed effect models, due to a combination of structure and error analysis of complex, and the differences of the heterogeneity of understanding, because the estimates and economic implications, resulting in the academic circles of random effects and fixed effects have not yet been finalized (Hongxing Zhang and Yandong Jia, 2006) ${ }^{\text {[20] }}$, for the random choice the effect or fixed effect, commonly used method is Hausman test. In this paper, Hausman test is used to find the fixed effect model. The result shows that the P value is less than 0.05 .

Table 4-3 shows the results of model checking. Model (1) test results show that, under the control of R\&D costs, main business income, enterprise age, total assets, employees factors, the $\mathrm{P}$ value of government subsidies is less than 0.05 , indicating that government subsidies can significantly promote enterprise innovation performance. Through the model (2) test results, we can see that the degree of geographical agglomeration has a significant positive impact on enterprise 
innovation performance, that is, the P value is less than 0.05 . In the model (3), the test results show that government subsidies have no significant impact on the agglomeration of enterprises' geographical regions. That is, the government subsidy policy does not produce the agglomeration effect market mechanism which is beneficial to the enterprise innovation, and the agglomeration effect which has a positive impact on the enterprise innovation performance is caused by other factors. Through the model (4) test results, it shows that the government subsidy policy and the degree of geographical agglomeration have a positive impact on the enterprise innovation performance, and the $\mathrm{P}$ value is less than 0.05 , which is significant at the $5 \%$ significant level. With the test of the three model results show that the government subsidy policy for the enterprise agglomeration effect is not significant, to determine whether the degree of agglomeration has a mediating effect between government subsidies and enterprise innovation performance, but also need to construct a new test statistic Sobel test. Constructing test statistics: $Z=\hat{a} \hat{b} / S_{a b}, S_{a b}=$ $\sqrt{\hat{a}^{2} S_{b}^{2}+\hat{b}^{2} S_{a}^{2}}$, where $\hat{a}$ and $\hat{b}$ respectively model (3) in the $\alpha 1$ and model (4) in the estimation of $\alpha 2, S_{a}$ and $S_{b}$ respectively, the standard error of $\hat{a}$ and $\hat{b}$. The calculated $|Z|$ value is 0.489 , less than the critical value of 0.9 , and the corresponding $\mathrm{P}$ value is greater than 0.05 . Therefore, the geographical agglomeration does not play a mediating role between the government subsidy policy and the enterprise innovation performance. Finally, combining the model (1) and model (5) , through the observation of the test results, found in the model (1) in Gov_subs and enterprise innovation performance positively related, while in the model (5) in Gov_subs and significant positive correlation with the performance of enterprise innovation, Gov_subs $\wedge 2$ and enterprise innovation performance is negatively correlated, so we can draw a conclusion of government subsidies and enterprise innovation performance is not in a simple linear relationship, but present the inverted "U" type.

Table 4-3. model test results

\begin{tabular}{|c|c|c|c|c|c|}
\hline variables & Model (1) & Model (2) & Model (3) & Model (4) & Model (5) \\
\hline Gov_subs & $1.2119 \mathrm{e}+00^{*}$ & - & $-1.8873 e-02$ & $1.2178 \mathrm{e}+00^{*}$ & $6.3832 \mathrm{e}+00 * * *$ \\
\hline Gov_subs ${ }^{\wedge 2}$ & - & 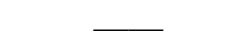 & - & - & $-2.3760 \mathrm{e}-05^{* * *}$ \\
\hline Geo_agg & - & $3.0594 \mathrm{e}-01^{*}$ & - & 3.1166e-01* & $\longrightarrow$ \\
\hline $\mathrm{RD}$ & $3.8731 \mathrm{e}-01^{* * *}$ & 3.8606e-01*** & $-4.7614 \mathrm{e}-03$ & $3.8879 \mathrm{e}-01^{* * *}$ & $3.9581 \mathrm{e}-01^{* * *}$ \\
\hline BI & $6.2134 \mathrm{e}-02^{* * *}$ & $6.2527 \mathrm{e}-02 * * *$ & $-3.4884 \mathrm{e}-04$ & $6.2242 \mathrm{e}-02^{* * *}$ & $6.2694 \mathrm{e}-02^{* * *}$ \\
\hline age & $2.0481 \mathrm{e}+03^{* *}$ & $1.2797 \mathrm{e}+03$ & $2.4747 \mathrm{e}+03 * * *$ & $1.2768 \mathrm{e}+03$ & $1.9809 \mathrm{e}+03^{*}$ \\
\hline assets & $2.3269 \mathrm{e}-01 * *$ & $2.3247 \mathrm{e}-01 * * *$ & $1.8819 \mathrm{e}-03$ & $2.3211 \mathrm{e}-01$ & $2.2817 \mathrm{e}-01^{* * *}$ \\
\hline staff & $-2.3552 \mathrm{e}+02 * * *$ & $-2.3745 \mathrm{e}+02 * * *$ & $3.6005 \mathrm{e}+00 * * *$ & $-2.3664 \mathrm{e}+02$ & $-2.3366 \mathrm{e}+02 * * *$ \\
\hline R-squared & 0.1526 & 0.1514 & 0.1862 & 0.1521 & 0.1542 \\
\hline
\end{tabular}

\section{Research Conclusions and Recommendations}

\section{1 research conclusions}

This paper selects the data of high-tech industry enterprises for empirical research, mainly focuses on the relationship between government subsidies and innovation performance, as well as whether agglomeration effect of market mechanism plays a mediating role between government subsidies and innovation performance, and draws the following conclusions:

The study shows (1) government subsidies have a significant positive impact on innovation performance, to a certain extent, promote the development of high-tech industry, government 
subsidies policy has the effect of innovation; further into government subsidies in the model two times, the study found that the relationship between government subsidies and enterprise innovation performance inverted "U" type relationship, indicating that the government subsidies play innovation effect the existence of the optimal threshold value, the government should be based on the actual situation of the enterprise or the real factors of moderate government subsidies to support, in order to give full play to the effect of a new government subsidies. (2) the classical agglomeration theory holds that agglomeration has spillover effect, which enables enterprises to improve productivity and innovation ability through continuous learning in agglomeration. This study shows that the agglomeration of enterprises in the geographical region has a positive impact on the enterprise innovation performance, and is conducive to the improvement of enterprise innovation level. There is agglomeration effect is conducive to innovation generation, from this perspective, the government should actively promote the agglomeration of enterprises in the region; (3) the government subsidies to enterprises agglomeration did not have a significant impact, the reason may be that the regional government competition similar policies follow up, the competition between the area policy incentives, promote agglomeration effect tends to weaken this is the policy, and even offset each other. In addition, the existing government industrial policies are mainly based on the selective industrial policy, and have obvious interference to the market. As an individual in the market economy, enterprises may consider more about the impact of market mechanism on the development of enterprises. (4) the enterprise agglomeration did not play a mediating role in the relationship between government subsidies and innovation performance, indicating that the government subsidy policy is not associated with the formation of agglomeration effects and market mechanism, has a certain degree of coordination between the two, and the formulation and implementation of government subsidy policy remains to be further improved.

\section{2 policy recommendations}

According to the study, recommendations are as follows: (1) Continuing to implement the policy of government subsidies to encourage firms to innovate, despite the existence of information asymmetry problem between government and enterprises, enterprises may release false information to defraud the government subsidies and other preferential policies, the government subsidy policy is facing a challenge. But the empirical results show that the government subsidy policy has a significant positive impact on the enterprise innovation performance, and can enhance the enterprise innovation performance. Therefore, the government subsidy policy is correct in the direction. (2) In view of the possible subsidy problem, the government should strengthen the management and supervision of the use of subsidy funds, and establish and improve the evaluation mechanism for the use of subsidy funds. The potential subsidy enterprises are carefully evaluated, and after the subsidy funds are issued, the enterprises enjoying the government subsidies are supervised in the process of practice, ensure that enterprises can improve their own innovation capability through government subsidies. (3) the empirical results show that the government subsidy policy not through the enterprise geographic agglomeration effect of the market mechanism to play a role in innovation, namely the government subsidy policy and enterprise agglomeration effect of market mechanism, but also reflect the lack of government subsidies from the side. The current industrial policy mainly in selective industrial policy, with strong intervention on the market, even tried to judge the government choose to replace the market mechanism, to make the industrial policy and market mechanism coordinated integration, it is necessary for the government to change the existing industrial policy, step by step makes selective industrial policy changes to the function of industrial policy.

\section{Research Limitations and Prospects}

This study focused on the relationship between government subsidies and innovation performance, and whether the agglomeration effect of market mechanism to play a mediating role between the government subsidies and innovation performance, get some relative conclusions, but 
there are still limitations, some problems need to be further studied: (1) government subsidies can extend in the transverse width. Government subsidies include financial allocation, financial discount, tax return and various special funds. Because of the limited access to data, there is no detailed classification of government subsidies. The future research can explore the impact of various forms of government subsidies. (2) government subsidies can be extended vertically. This study finds that the relationship between government subsidies and innovation performance is nonlinear, which shows that there is an optimal threshold for government subsidies innovation effect, which can further study the extent to which the government subsidies can make their innovation effect best, and is conducive to the efficient use of government subsidies. (3) according to the standard and normative data of the database and the limitation of data acquisition, the data used in the year are relatively old. Based on the earlier government subsidy policy, the paper proposes guidance for the realistic policy. In the case that conditions permit access to data in the next year, future studies can use more comprehensive data.

\section{Acknowledgments}

This work was financially supported by Rongjian Yu fund.

\section{References}

[1] Tongliang An, Shaodong Zhou, Jiancai Pi. R\&D subsidies for independent innovation Chinese enterprise incentive effect [J]. Economic Research, 2009 (10) 87-98

[2] Hewitt-Dundas N, Roper S. Output additionality of public support for innovation: Evidence for Irish manufacturing plants [J]. European Planning Studies, 2010, 18(1) 107-122.

[3] Shuming Ren, Jing Zhang. Subsidies, rent-seeking costs and the added rate —An empirical study based on Chinese equipment manufacturing enterprises[J]. Management World, 2013, (10) 118-129

[4] Fornahl, D. and Broekel, T. and Boschma, R. "What Drives Patent Performance of German Biotech Firms? The Impact of R\&D Subsidies, Knowledge Networks and Their Location” [J]. Paper in Regional Science, 2011, 90(2) 395 -418.

[5] Jun Wang. An empirical study on the impact of R\&D subsidies on firm R\&D investment and innovation output [J]. Science Research, 2010, 28 (9) 1368-1374

[6] Cui Zhang. Industrial agglomeration and Innovation: a review of propositions and analysis of micro mechanism [J]. Scientific Management Research, 2010, (3) 1-4

[7] Pinch S., Henry N., Jenkins M., el al. From Industrial Districts Knowledge Clusters: A Model of Knowledge Dissemination and Competitive Advantage in Industrial Agglomeration [J]. Journal of Economic Geography, 2003 (3) 373-388

[8] Von Zedtwitz M. and Heimann P. Innovation in clusters and the liability of foreignness of international R\&D [J]. Europe and Asia, 2006, 101-122

[9] Beaudry C. and Breschi S. Are firms in clusters really more innovative? [J]. Economics of Innovation \& New Technology, 2003, 12(4) 325-342

[10] Schemgell T., Barber M. Distinct spatial characteristics of industrial and public research collaborations: Evidence from the 5th EU framework programme [J]. Annals of Regional Science,2011, 46: 247-266

[11] Zi Wu. The localization of knowledge spillovers and regional innovation performance: a knowledge spillover model based on geographical distance [J]. Science and Technology 
Progress and Countermeasures, 2011, (14) 30-34

[12] M Svetlicic. Multinational Enterprise and the Global Economy[J]. Journal of International Business Studies,2010,25(1) 190-193

[13] Fujita M, Thisse J F. Economics of agglomeration: cities, industrial location, and globalization [M]. Cambridge University Press, 2013,10(4):339-378

[14] Guoqiang Cui. Trends and influencing factors of regional agglomeration of China's manufacturing industry [D]. Shanghai Jiao Tong University, 2012, 47-60

[15] Lei Xu. Government subsidies, manufacturing agglomeration and industrial transfer-theoretical analysis based on C-P model [J]. East China Economic Management, 2013, (9) 83-87

[16] Chenguang Hu, Huifang Cheng, Bin Yu. "Promising government" and the evolution of agglomeration economic circle-An analysis framework based on the agglomeration economic circle of Yangtze River Delta [J]. Management World, 2011 (2) 61-69

[17] Loren Brandt, Johannes Van Biesebroeck, Yifan Zhang. Challenges of working with the Chinese NBS firm-level data [J] China Economic Review, 2014 (30) 339-352

[18] Martin, P., Mayer, T., Mayneris, F. Spatial Concentration and Plant-level Productivity in France [J]. Journal of Urban Economics, 2011, 69 (2) 182-195

[19] Zhonglin Wen, Baojuan Ye. Mediating effect analysis: methods and models for the development of [J]. Psychological Science, 2014, 22 (5) 731-745

[20] Hongxing Zhang, Yandong Jia. New ideas for setting up Panel Data model_—Unification of fixed effect and random effect[J]. Quantitative Economic Technology and Economic Research, 2006, (6) 148-154 